\title{
Proposição de um modelo para análise dos fatores de risco em projetos de implantação da metodologia lean
}

\author{
Proposition of a model for the evaluation of risk factors in lean \\ methodology project implementation
}

\author{
Jonatas Ost Scherer Ost Scherer ${ }^{1}$ \\ José Luis Duarte Ribeiro'
}

\begin{abstract}
Resumo: A gestão dos riscos envolvidos em projetos de implantação da metodologia lean é importante para reverter o baixo percentual de sucesso encontrado em tais projetos. Este artigo apresenta três contribuições principais ao tema: (i) identificação dos fatores de risco em projetos de implantação da metodologia lean; (ii) levantamento da intensidade do relacionamento entre os fatores identificados; e (iii) algoritmo para a estimativa da probabilidade de sucesso da implantação, considerando a condição dos fatores e intensidade do relacionamento entre eles. O modelo proposto foi baseado na revisão da literatura e na opinião de especialistas da academia e da indústria. Ele utiliza preceitos de confiabilidade, em que os fatores de risco são modelados como um sistema série-paralelo. O modelo, testado em três empresas, apresentou resultados coerentes com as incertezas e riscos destes projetos. Identificou também os fatores de risco críticos para o projeto, considerando a sinergia entre os fatores.
\end{abstract}

Palavras-chave: Produção enxuta. Gestão de riscos.

\begin{abstract}
Managing risks associated with lean methodology implementation is important in order to overcome the low success rate for such projects. This paper presents three main contributions to this subject: (i) identification of risk factors of lean methodology implementation projects, (ii) degree of relationship between the factors identified, and (iii) algorithm for estimating the probability of a successful lean methodology project implementation, considering the type of factors and the degree of relationship between them. The model proposed was based on literature review and views of experts from academia and industry. It uses principles of reliability, in which the risk factors are modeled as a series-parallel system. The model tested in three companies showed results consistent with the uncertainties and risks of such projects. In addition, it identified the project critical risk factors considering the synergy between the factors.
\end{abstract}

Keywords: Lean manufacturing. Risk management.

\section{Introdução}

A desaceleração da economia, o aumento da competição, a incapacidade de inovar e atender às necessidades dos clientes e a falha da tecnologia/ sistema estão entre os principais riscos que as empresas terão pela frente conforme Aon (2011). De acordo com FT (FINANCIAL..., 2010), 62\% dos executivos consideraram suas empresas como não efetivas ou moderadamente efetivas em integrar informações de risco em suas decisões gerenciais, sendo que esse valor alcança $74 \%$ para a indústria manufatureira.

Para Abt et al. (2010) e Aven e Kristensen (2005), a análise de risco deve prover suporte às decisões gerenciais. Deloitte (2009) verificou que $82 \%$ das empresas consideram que a área de gestão de riscos deveria formalmente aprovar novos produtos, e $64 \%$ das empresas consideram que essa área deveria aprovar a entrada em novos negócios. Ernst \& Young (2010) apresentam resultados indicando que $60 \%$ das empresas da indústria financeira realizaram mudanças nas suas estruturas e processos de gestão de risco. Isso ressalta a importância da gestão de risco e contribui para o crescente interesse na disciplina, conforme identificado por Arena, Arnaboldi e Azzone (2010).

Ainda conforme esses autores, a análise de riscos pode ser realizada utilizando ferramentas qualitativas, quantitativas ou utilizando métodos mistos. Jogulu e Pansiri (2011) ressaltam os benefícios de utilizar os métodos mistos em pesquisas na área de gestão.

A gestão de riscos é importante quando ocorrem mudanças estruturais e organizacionais, como a implantação da metodologia lean (GODINHO FILHO; FERNANDES, 2004; SAURIN; RIBEIRO;

\footnotetext{
${ }^{1}$ Departamento de Engenharia de Produção e Transportes, Universidade Federal do Rio Grande do Sul - UFRGS, CEP 90040-060, Porto Alegre, RS, Brasil, e-mail: josoceania@yahoo.com.br
}

Recebido em 25/7/2012 — Aceito em 12/3/2013

Suporte financeiro: Nenhum. 
MARODIN, 2010), já que estas são atividades complexas. McKinsey (2010) verificou que 43\% das empresas que realizaram mudanças organizacionais subestimaram o tempo necessário de implantação. Constatando também que apenas $16 \%$ das empresas atingiram completamente os resultados esperados dentro do tempo estipulado.

Ao implantar a metodologia lean, as empresas devem estar cientes e preparadas para os riscos associados. Badurdeen, Wijekoon e Marksberry (2011), Bhasin e Burcher (2006) e Boyle, Scherrer-Rathje e Stuart (2011) ressaltam o baixo percentual de sucesso na implantação de sistemas lean. Assim, é importante que a empresa gerencie os riscos durante a implantação da metodologia lean. Este trabalho tem por objetivo a proposição de um modelo que estabelece os relacionamentos entre os fatores de risco, indicando a probabilidade de sucesso do projeto de implantação da metodologia. Esse modelo pode auxiliar na avaliação qualitativa e quantitativa de projetos de implantação da metodologia lean, fornecendo subsídios para decisões gerenciais durante o projeto de implantação.

O modelo desenvolvido utiliza conceitos da teoria de confiabilidade. Assim, inicialmente é apresentada uma revisão sobre sistemas série-paralelo e sobre os elementos importantes na avaliação do grau lean de uma organização. A seguir é apresentada a metodologia utilizada para a realização do trabalho. A seção 5 apresenta a construção do modelo, caracteriza as empresas em que ele foi testado e reporta os resultados e a análise. Por fim, a seção 6 apresenta as conclusões finais do trabalho.

\section{Sistema série-paralelo}

Considerando os preceitos da confiabilidade, um sistema é caracterizado por um conjunto de componentes, com funções operacionais específicas, integrados em um projeto, visando realizar uma atividade de forma satisfatória. A confiabilidade deste sistema pode ser definida como a probabilidade do sistema atender ao propósito para o qual foi projetado. Os sistemas em série são caracterizados pelo fato de a falha de um componente resultar na falha total do sistema, enquanto nos sistemas em paralelo, a falha total do sistema só ocorrerá se todos os componentes falharem (FOGLIATTO; RIBEIRO, 2009; KRISHNA; SHARMA, 2008; RAUSAND; HOYLAND, 2004). A Figura 1 ilustra os diagramas de confiabilidade referentes a sistemas série e paralelo, sendo $\mathrm{i}=1,2, \ldots, \mathrm{n}$.

Um sistema série-paralelo consiste em um arranjo de $\mathrm{n}$ subsistemas em série, cada um deles contendo $\mathrm{m}$ unidades em paralelo. A Figura 2 representa um sistema série-paralelo, sendo $\mathrm{i}=1,2, \ldots, \mathrm{m}$ e $\mathrm{j}=1,2, \ldots, \mathrm{n}$.

Conforme Elsayed (1996) e Rausand e Hoyland (2004), a confiabilidade de um sistema série-paralelo é obtida pela Equação 1.

(a) Sistema em série:

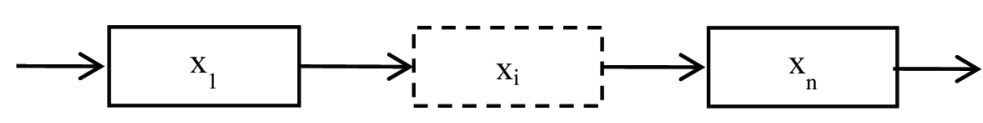

(b) Sistema em paralelo:

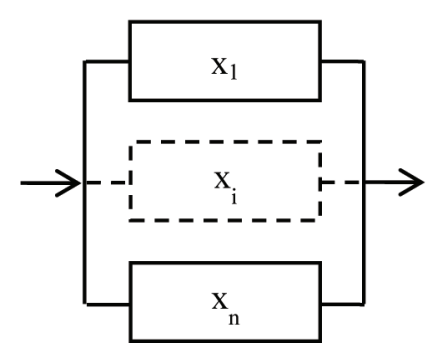

Figura 1. (a) sistema em série e (b) sistema em paralelo. Fonte: Elsayed (1996).

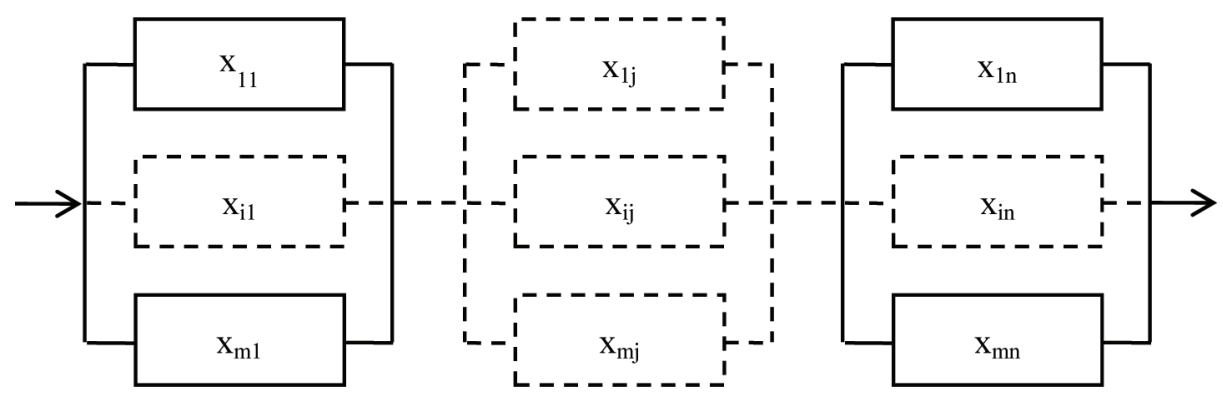

Figura 2. Sistema série-paralelo. Fonte: Elsayed (1996). 


$$
R_{S}=\prod_{j=1}^{n}\left[1-\prod_{i=1}^{m}\left(1-p\left(x_{i j}\right)\right)\right]
$$

Em que: $R_{s}$ é a confiabilidade do sistema sérieparalelo, enquanto $p\left(x_{i j}\right)$ é a confiabilidade ou probabilidade de sucesso do componente $x_{i j}$.

\section{Avaliação do grau lean}

A avaliação do projeto lean é um importante indicador para auxiliar decisões gerenciais, motivando assim o desenvolvimento de diferentes ferramentas (Quadro 1).

Bhasin (2011) propõe um modelo de auditoria para avaliar em qual estágio da implantação da metodologia lean a empresa se encontra. A auditoria é baseada em doze categorias que refletem a metodologia lean, avaliadas por meio de 104 questões. Para cada questão, o auditor atribui um índice entre zero e dez conforme a situação da empresa. A soma da pontuação indica em qual dos sete estágios de implantação propostos pelo modelo a empresa se encontra.

Goodson (2002) sugere a utilização de onze categorias para avaliar a aderência da empresa à metodologia lean. A avaliação é realizada por meio de dois questionários respondidos por um grupo formado por quatro ou cinco integrantes. Inicialmente o grupo avalia a situação da empresa nas onze categorias, atribuindo valores entre um e onze conforme a situação da empresa. O segundo questionário contém 20 questões, referentes às 11 categorias, para as quais o grupo de avaliação responderá sim ou não, conforme a situação da empresa. A soma das avaliações do questionário um e o número de vezes que foi respondido sim no questionário dois indicam quão lean está a empresa.

A utilização do benchmarking como ferramenta para avaliação da implantação da metodologia lean é proposta por Gurumurthy e Kodaly (2009). Esses autores definiram 65 elementos da metodologia lean, em relação aos quais a empresa deve avaliar sua utilização, comparando com a utilização destes por uma empresa de ponta que será seu benchmark. Propõe também a utilização de 89 indicadores de desempenho para fatores críticos de sucesso, para os quais a empresa deve avaliar a situação atual e desejada.

O modelo de Ray et al. (2006) utiliza análise fatorial para definir quantitativamente quão lean está a empresa. Estes identificaram padrões de relacionamento entre variáveis quantificáveis, como inventário de produtos, para definir variáveis que não podem ser diretamente medidas, como a situação da empresa relativa à metodologia lean.

Singh, Garg e Sharma (2010) propõem a avaliação do grau lean da empresa por meio de cinco parâmetros. A empresa é avaliada por uma equipe de avaliadores, todos com conhecimento na metodologia, sendo que a avaliação de cada um destes poderá ter pesos diferentes, conforme a especialidade e experiência do avaliador. Cada avaliador atribuirá um grau entre 0 e 100 para cada um dos parâmetros e uma função triangular fuzzy é utilizada na modelagem, sendo mais tarde convertidos os valores obtidos para um índice de quão lean está a empresa.

Soriano-Meier e Forrester (2002) utilizam um questionário estruturado para avaliar o grau de implantação da metodologia lean. O modelo utiliza nove princípios da produção enxuta para avaliar a adoção desta e dois princípios para avaliar o comprometimento gerencial com a implantação. O avaliador responde a cada questão com um grau entre 1 e 7 , conforme o grau de aderência da empresa à questão. Os graus atribuídos a estes princípios são utilizados como variáveis independentes para o cálculo da variável dependente grau de implantação da metodologia lean.

Taj (2008) utiliza nove categorias para avaliar a implantação da metodologia lean. $\mathrm{O}$ avaliador utiliza uma escala de zero a quatro para responder de 3 a 6 questões associadas a cada uma das nove categorias, considerando o estado atual e o estado desejado, possibilitando, desta forma, desenhar uma carta ilustrando os gaps entre o estado atual e o desejado.

Os métodos citados avaliam o grau lean da empresa, baseados em práticas e características específicas dessa metodologia. No entanto, esses métodos: (i) não consideram a sinergia entre fatores; (ii) não estão voltados para a fase imediatamente anterior

Quadro 1. Métodos de avaliação lean.

\begin{tabular}{|l|l|}
\hline \multicolumn{1}{|c|}{ Autor } & \multicolumn{1}{c|}{ Método } \\
\hline Bhasin (2011) & Auditoria considerando 12 categorias para identificar o estágio de implantação \\
\hline Goodson (2002) & Auditoria considerando 11 categorias \\
\hline Gurumurthy e Kodaly (2009) & Utilização de técnicas de benchmarking \\
\hline Ray et al. (2006) & Técnicas de análise fatorial para definir o grau lean da empresa \\
\hline Singh, Garg e Sharma (2010) & Auditoria considerando cinco parâmetros \\
\hline Soriano-Meier e Forrester (2002) & Avaliação do grau lean baseada em nove princípios lean \\
\hline Taj (2008) & Avaliação do estado atual referente ao planejado, considerando nove áreas-chave. \\
\hline
\end{tabular}


à implantação; e, assim, (iii) não fornecem uma avaliação da probabilidade de sucesso da implantação.

\section{Metodologia}

Este trabalho compreende uma pesquisa de natureza aplicada (SILVA; MENEZES, 2001), pois busca gerar conhecimento para aplicação prática em projetos de implantação de sistemas lean. Para tanto, foi utilizada uma abordagem qualiquantitativa, uma vez que fatores de risco ao sucesso do projeto foram identificados qualitativamente, enquanto a relação entre eles foi quantificada. Conforme Malina, Nørreklit e Selto (2011), a combinação de métodos qualitativos e quantitativos permite explorar características mais complexas que podem estar presentes nos sistemas em estudo. $\mathrm{O}$ uso combinado dessas abordagens tem apresentado uma tendência de crescimento no estudo de fenômenos complexos da área de gestão e negócios (CAMERON; MOLINA-AZOLIN, 2011). Ademais, Yin (2004) ressalta que métodos qualitativos são particularmente adequados quando os objetivos dos pesquisadores incluem a construção de teorias. O procedimento aplicado envolveu a pesquisa bibliográfica, para o estabelecimento do modelo, e testes de campo para a avaliação. O objetivo da pesquisa é explicativo, pois é proposto um modelo que permite estimar a probabilidade de sucesso da implantação de um projeto lean, considerando os vários elementos que influenciam na implantação.

$\mathrm{O}$ teste do modelo proposto foi realizado em três empresas manufatureiras multinacionais de grande porte ( $>500$ funcionários, conforme Sebrae - www. sebrae.com.br) localizadas na região sul do Brasil. Estas estavam em diferentes estágios de implantação da metodologia. Em uma delas, o projeto de implantação da metodologia lean era corporativo, enquanto nas demais era localizado.

A primeira etapa consistiu na identificação dos principais fatores de risco associados à implantação de sistemas lean por varredura horizontal das bases de dados online Emerald, Science Direct, SciELO e Springer. A pesquisa foi realizada utilizando as expressões constituídas pelas palavras-chave: lean implementation; toyota implementation; project risk management; risk management methodology; e project management. As cinco expressões foram buscadas de forma independente, ou seja, para cada base de dados foram pesquisadas as cinco expressões. Foram considerados apenas artigos publicados em revistas e jornais científicos publicados a partir de 2005, sendo desconsiderados editoriais, sínteses de livros, livros, artigos publicados em conferências, dissertações e teses, pois estes estão sujeitos à avaliação menos rigorosa quando comparados aos periódicos científicos.

Os resultados obtidos junto à base de dados foram ordenados pelo critério relevância (a relevância é maior quando o termo aparece diretamente no título, seguido das palavras-chave e do resumo), limitando-se a análise aos 200 primeiros resultados para cada expressão pesquisada. A seguir, foram identificados os artigos aplicados ao setor de manufatura, escopo deste trabalho. Os resumos foram lidos e aqueles pertinentes ao objetivo deste trabalho, analisados. Durante esta análise, identificaram-se os principais fatores de risco ou fatores críticos para o sucesso do projeto de implantação de sistemas lean.

A segunda etapa consistiu na avaliação da lista de fatores de risco. Para tanto, foram realizadas entrevistas semiestruturadas, que constituem um instrumento adequado para verificar o pensamento de gestores (QU; DUMAY, 2011). As entrevistas envolveram dois acadêmicos e três profissionais de nível gerencial de duas das empresas estudadas. Nas entrevistas, verificou-se a visão dos especialistas em relação aos fatores de risco em um projeto de implantação da metodologia lean, bem como, a representatividade dos 14 fatores levantados sobre a possibilidade de sucesso do projeto de implantação da metodologia lean. As duas empresas foram selecionadas para consolidação dos fatores de risco por serem de classe mundial, seus profissionais serem experientes na implantação de práticas lean e dominarem o tema.

Para construção do modelo de relacionamento entre os fatores de risco, foram consultados cinco acadêmicos especialistas em lean. A escolha de especialistas da academia ocorreu por estes terem um conhecimento teórico aprofundado do assunto, associado à grande experiência prática em projetos junto a empresas. Por meio de formulário estruturado, os especialistas indicavam quanto a situação desfavorável relativa a um dos fatores de risco poderia ser compensada pelos demais fatores de risco. Estes atribuíram um valor entre 0 e 1 para cada relação analisada, sendo 0 , quando o fator de risco não era compensado em nenhum grau pelo outro fator considerado, e 1, quando o fator de risco era plenamente compensado pelo outro fator. Assim, para cada um dos fatores de risco, avaliou-se o efeito sinérgico com os demais fatores. A partir destas ponderações, foi construído um modelo de avaliação que apresenta a estrutura de um sistema série-paralelo, como será mais bem explicado na seção de resultados.

Ainda na fase de construção, o modelo de relacionamento foi analisado por dois profissionais de uma das empresas estudadas e por três especialistas da academia. Estes especialistas foram questionados sobre a intensidade dos relacionamentos apresentados pelo modelo, concordando ou indicando quais relações deveriam ser revistas. O modelo foi ajustado sempre que coincidiram as indicações de mudança feitas por mais de um desses especialistas.

O modelo de avaliação foi testado junto a três empresas. Visando considerar a incerteza decorrente da avaliação dos entrevistados na empresa, foram 
entrevistadas mais de uma pessoa por empresa. Por meio de formulário estruturado, os responsáveis pela empresa atribuíam um valor entre 0 e 1 , conforme a situação da empresa em relação a cada fator de risco. Ademais, indicavam evidências para cada estimativa, visando embasar suas avaliações. A mediana dos valores estimados pelos avaliadores da empresa para cada fator de risco foi inserida no modelo, resultando em uma probabilidade de sucesso associada ao processo de implantação da metodologia lean.

Por fim, as avaliações foram apresentadas às empresas e discutidas, visando assim verificar a consistência dos resultados obtidos. Conforme os resultados e discussão com as empresas, foram realizadas a análise da utilidade e a validade do modelo de avaliação do processo de implantação da metodologia lean.

\section{Resultados}

\subsection{Identificação dos fatores de risco}

Os fatores de risco são ameaças ao sucesso da implantação. Conforme Aloini, Dulmin e Mininno (2007), a identificação dos fatores de risco na literatura pode ser dificultada pelos diferentes termos utilizados, como: fatores de risco; fatores críticos de sucesso; ou fatores de incerteza; entre outros. A análise considerou todas essas variações, sendo utilizado o termo fatores de risco como padrão para agrupá-las.

A leitura dos resumos dos resultados das bases de dados gerou uma avaliação mais aprofundada de 161 artigos. Analisando esta literatura, foram identificados 14 fatores de risco associados à implantação de sistemas lean em 39 artigos.

\subsubsection{Alinhamento estratégico}

A implantação de sistemas lean, mais especificamente de seus resultados e consequências, deve estar alinhada com a estratégia da empresa. Emiliani e Stec (2005) identificaram a falta de integração estratégica como um erro comum durante a implantação de sistemas lean. A aplicação de ferramentas lean deve gerar melhorias para toda a empresa e seus usuários, não apenas produzir ganhos localizados. Sim e Rogers (2009) ressaltam que todas as iniciativas devem estar claramente relacionadas com a missão e metas da empresa.

\subsubsection{Capacidade financeira}

A empresa deve estar preparada para os custos de implantação do projeto. Estes podem variar conforme o porte e o nível das práticas já implantadas na empresa. Achanga et al. (2006) citam a importância para o sucesso da implantação da disponibilidade de recursos para investimentos em treinamento e consultoria, bem como, para implantação de alterações.

\subsubsection{Capacidade e qualidade dos fornecedores}

A implantação da filosofia lean envolve stakeholders externos à empresa, por exemplo, fornecedores. Olsson (2007) ressalta a necessidade de entender como outras organizações afetam os objetivos do projeto, tanto em termos de riscos como de oportunidades. Houshmand e Jamshidnezhad (2006) citam a importância da agilidade e eficiência da cadeia de suprimentos para a empresa. Mohammed, Shankar e Banwet (2008) e Soon e Udin (2011) ressaltam os desafios de criar uma cadeia de suprimentos flexível, importante para a metodologia lean. Boyle, Scherrer-Rathje e Stuart (2011) apontam o risco da quebra da cadeia de suprimento para a empresa. Stavrulaki e Davis (2010) ressaltam que a estrutura da cadeia de suprimentos deve estar adequada às características do processo de produção.

\subsubsection{Rede de transportes}

Arrto et al. (2008) identificaram a existência de outros envolvidos no projeto, que não empresas, com interesses que podem influenciar o resultado deste. Sanchez-Rodrigues, Potter e Naim (2010) e Wu, Blackhurst e Chidambaram (2006) apontam o risco gerado pelas regulações governamentais sobre o sistema logístico em termos de taxações, regulação e integração dos modais. Christopher et al. (2011) identificam a infraestrutura de transportes como um risco para a empresa. Sanchez-Rodrigues, Potter e Naim (2010) citam a ameaça logística decorrente dos congestionamentos nas vias.

\subsubsection{Cultura organizacional}

Para Achanga et al. (2006), a implantação de sistemas lean exige uma cultura organizacional de melhoria proativa, que aceite as mudanças e possua a habilidade para gerir ambientes diversos. Jeyaraman e Teo (2010) ressaltam a importância da mudança de atitude dos colaboradores advinda da metodologia. Bhasin e Burcher (2006) acrescentam a necessidade de fomentar os princípios lean também por meio da cadeia de valor. Conforme Marksberry et al. (2010), é importante entender porque a técnica existe, para, assim, definir a cultura organizacional necessária. Yamamoto e Bellgran (2010) sugerem que deve ser criado um ambiente que fomente a necessidade das melhorias decorrentes da implantação do sistema lean, para, desse modo, transpor barreiras à implantação da metodologia. 


\subsubsection{Comprometimento da alta diretoria}

O comprometimento via suporte e participação da alta diretoria é fator-chave para o sucesso de um projeto. Zwikael (2008a, b) verificou que o suporte da alta diretoria está diretamente relacionado ao sucesso do projeto. Acrescenta ainda que este suporte adquire diferentes formas conforme características da empresa. Gattiker e Carter (2010) ressaltam a importância do comprometimento da alta diretoria para alcançar o comprometimento de outros stakeholders envolvidos, enquanto Young e Jordan (2008) consideram o comprometimento da alta diretoria o fator crítico mais importante para o sucesso de um projeto.

\subsubsection{Comprometimento dos colaboradores}

As médias e baixas gerências também são protagonistas no sucesso da implantação da metodologia lean. Scherrer-Rathje, Boyle e Deflorin (2009), Herron e Hicks (2008) e Sim e Rogers (2009) ressaltam o importante papel exercido pelas gerências para o sucesso do projeto. Worley e Doolen (2006) e Jeyaraman e Teo (2010) frisam a importância da função exercida pelos gestores de envolver os colaboradores e disseminar a metodologia para o sucesso da implantação. Achanga et al. (2006) acrescentam que os gestores devem possuir as habilidades necessárias para realizar sua tarefa. Anand e Kodali (2009) e Olivella, Cuatrecasas e Gavilan (2008) corroboram a importância do envolvimento das pessoas no processo de implantação de sistemas lean. A participação destas faz parte dos princípios lean e deve ser fomentada para assegurar o sucesso do projeto de implantação da metodologia e de sua continuidade.

\subsubsection{Liderança}

Emiliani e Stec (2005) verificaram que o comportamento das lideranças inconsistente com o apregoado pela metodologia, bem como a falta de participação das lideranças, levam a resultados insatisfatórios na implantação de sistemas lean. Achanga et al. (2006) ressaltam que é função das lideranças facilitarem a integração de toda a estrutura da empresa, além de fornecer uma visão e estratégia adequadas a uma implantação correta da metodologia.

\subsubsection{Treinamento}

Achanga et al. (2006) afirmam que as pessoas envolvidas no projeto devem possuir as habilidades necessárias à correta implantação do sistema lean, assim como o nível dos colaboradores da empresa deve ser adequado às novas tecnologias a serem implantadas. Lam e Chua (2005) identificam como uma ameaça ao sucesso da implantação a falta ou nível insuficiente de conhecimento. Adicionam também a inaptidão de aprender com os erros como ponto que pode levar ao fracasso da implantação. Burduk e Chlebus (2006) acrescentam a relevância da expertise e habilidades dos gestores para o projeto de implantação. Para o sucesso da implantação de um sistema lean, o treinamento deve ser abrangente em termos de conteúdo e de envolvidos, bem como ser efetivo. Jeyaraman e Teo (2010), Bhasin e Burcher (2006), Sawhney et al. (2010), Mathaisel (2005), Olivella, Cuatrecasas e Gavilan (2008), e Lam e Chua (2005) ressaltam a importância do treinamento para efetivação da metodologia.

\subsubsection{Comunicação}

A comunicação exerce papel fundamental em todo projeto conforme afirmam Sim e Rogers (2009). Para Worley e Doolen (2006), a comunicação deve ocorrer em duas vias entre os diferentes níveis, bem como deve atingir todas as áreas da empresa. Jeyaraman e Teo (2010) ressaltam que a comunicação é importante para informar o andamento do projeto e divulgar as metas e prazos aos envolvidos na implantação da metodologia. Karlsen (2010) realça a função de reduzir a assimetria de informação que a comunicação realiza, além de contribuir para construir um ambiente colaborativo, respeitoso e de confiança entre os envolvidos no projeto. Aoki (2008) ressalta o papel da comunicação para disciplinar os colaboradores, bem como o papel dos gerentes em facilitar comunicação intrafuncional. Atkinson, Crawford e Ward (2006) acrescentam que a falta de informação e ambiguidade nesta são fontes de incerteza que devem ser consideradas na elaboração do plano de gestão de riscos do projeto.

\subsubsection{Configuração do trabalho}

Treville e Antonakis (2006) sugerem que a configuração do trabalho conforme a metodologia lean pode contribuir para o nível de motivação dos colaboradores. Porém, este grau de motivação pode ser limitado caso a configuração seja excessivamente lean. Conti et al. (2006) ressaltam que a metodologia lean em si não é estressante para os trabalhadores, mas o nível de estresse é influenciado pelas decisões e comportamentos gerenciais.

\subsubsection{Autonomia dos colaboradores}

A participação dos colaboradores é parte do sistema lean. Scherrer-Rathje, Boyle e Deflorin (2009) identificaram a falta de autonomia ou a liberdade para os colaboradores realizarem mudanças necessárias no processo como um dos fatores críticos para o sucesso da implantação de sistemas lean. 


\subsubsection{Visão holística}

Ao planejar e executar a implantação, a empresa e seu entorno devem ser considerados. Mathaisel (2005) cita a importância de ver a empresa como um todo durante a implantação a fim de evitar que certos setores sejam desconsiderados. Para Emiliani e Stec (2005), entender o sistema lean como algo restrito à manufatura, e não como um sistema de gestão, pode levar ao fracasso desta. Já Olsson (2007) ressalta a importância de desenvolver uma visão holística do projeto para execução do plano de gestão de risco.

\subsubsection{Gestão do projeto}

Papke-Shields, Beise e Quan (2010) verificaram que o uso das técnicas de gestão de projeto está diretamente relacionado ao sucesso deste. Bhasin e Burcher (2006) identificaram a falta de adequado sequenciamento das etapas de implantação da metodologia lean como um fator potencial para o fracasso do projeto. Howell, Windahl e Seidel (2010) enfatizam que nem todos os projetos são iguais e, portanto, devem ser estruturados e geridos conforme suas peculiaridades.

Para Scherrer-Rathje, Boyle e Deflorin (2009) e Olivella, Cuatrecasas e Gavilan (2008), a implantação deve ser monitorada continuamente; além disto, sugerem que seja realizado o reconhecimento dos colaboradores pelas metas intermediárias atingidas. Jeyaraman e Teo (2010) acrescentam que um sistema de reconhecimento e premiação encoraja o envolvimento dos colaboradores. Kutsch (2008) verificou que os gestores de projeto tendem a negar, evitar, ignorar e adiar a gestão dos riscos do projeto. Ademais, Camprieu, Desbiens e Feixue (2007) verificaram que há diferenças significativas na forma como as pessoas em diferentes sociedades percebem e avaliam o risco.

O Quadro 2 compila os fatores de risco e suas referências. As respostas espontâneas dos profissionais em relação aos fatores de risco/sucesso/críticos estavam contempladas nos 14 fatores de risco apresentados. Os entrevistados ressaltaram a importância do envolvimento e uso do conhecimento de todas as pessoas da empresa no projeto de implantação. Destacaram a necessidade de um ambiente propício e coerente com a metodologia, a importância de um plano de implantação, assim como da divulgação dos resultados parciais obtidos durante as etapas do processo de implantação. Os 14 fatores de risco apresentados aos profissionais foram considerados por estes como representativos da realidade encontrada em projetos de implantação lean.

\subsection{Construção do modelo}

O modelo para avaliação do projeto de implantação da metodologia lean foi construído baseado no cenário ilustrado no Quadro 3.
O sucesso do projeto de implantação da metodologia lean dependerá da situação da empresa referente aos 14 fatores de risco identificados. Conforme verificado na literatura, a inaptidão total da empresa diante de um fator de risco irá bloquear algum princípio ou prática lean e deve levar ao fracasso do projeto de implantação da metodologia. Além disto, a sinergia entre os fatores de risco também impactam a probabilidade de sucesso do projeto de implantação, pois a deficiência em determinado fator pode ser compensada pelos demais fatores. Assim, a probabilidade de sucesso do projeto de implantação da metodologia lean pode ser calculada por meio dos conceitos de confiabilidade.

A estrutura de avaliação proposta neste artigo baseia-se no sistema série-paralelo. Conforme a proposta de avaliação, esse sistema consiste de 14 subsistemas em série, sendo cada um composto por 14 componentes em paralelo. Os subsistemas em paralelo são formados pela situação da empresa referente ao fator de risco e a compensação que pode ser fornecida pelos demais fatores de risco (Figura 3). A situação da empresa relativa ao fator de risco foi obtida por um processo de autoavaliação, no qual a empresa atribuiu um valor entre 0 e 1 para cada fator considerado. E a compensação decorrente do efeito dos demais fatores foi definida como o produto do grau de compensação fornecido por esses fatores, configurando a situação de sistema em paralelo. O grau de compensação também foi avaliado por especialistas usando uma escala entre 0 e 1 , que pode ser considerada a probabilidade do fator $i$ prover uma compensação satisfatória no caso de deficiência no fator $j$.

A modelagem proposta permite a utilização das equações da confiabilidade de um sistema sérieparalelo a fim de determinar a probabilidade de sucesso do projeto de implantação. Vale observar que cada subsistema do modelo apresenta um valor corrigido para a situação concernente ao correspondente fator de risco, considerando a sinergia entre os fatores, permitindo a identificação de forma mais efetiva dos pontos fracos do projeto de implantação. A compensação decorrente da sinergia entre os fatores de risco estabelece redundância em cada subsistema, oportunizando aos gestores atuarem indiretamente sobre um ou mais fatores de risco, visando aumentar a probabilidade de sucesso do projeto de implantação.

A probabilidade de sucesso do projeto de implantação da metodologia lean (PS) calculada pelo modelo é obtida pela Equação 2.

$$
P S=\prod_{j=1}^{14}\left[1-\prod_{j=1}^{14}(1-S i \times C i j)\right]
$$

Em que $P S$ é a probabilidade de sucesso do projeto de implantação da metodologia lean; Si é a autoavaliação da empresa referente ao fator de risco $i$; e $C i j$ é a compensação que o fator i pode prover ao fator $j$ no caso deste último apresentar deficiências. Essa compensação é calculada como o produto 
Quadro 2. Fatores de risco ao sucesso da implantação da metodologia lean.

\begin{tabular}{|c|c|c|}
\hline \multicolumn{2}{|r|}{ Fator de Risco } & Referências \\
\hline $\begin{array}{l}\text { 1. Alinhamento } \\
\text { estratégico }\end{array}$ & $\begin{array}{l}\text { Conceitos, resultados e consequências da implantação do } \\
\text { sistema lean devem estar alinhados com a estratégia da } \\
\text { empresa. }\end{array}$ & $\begin{array}{c}\text { Emiliani e Stec (2005) e Sim e } \\
\text { Rogers (2009) }\end{array}$ \\
\hline $\begin{array}{l}\text { 2. Capacidade } \\
\text { financeira }\end{array}$ & $\begin{array}{l}\text { Condições financeiras para custear o projeto de } \\
\text { implantação. }\end{array}$ & Achanga et al. (2006) \\
\hline $\begin{array}{l}\text { 3. Capacidade } \\
\text { e qualidade dos } \\
\text { fornecedores }\end{array}$ & $\begin{array}{l}\text { Disponibilidade de fornecedores capacitados a fornecer } \\
\text { conforme as necessidades de qualidade e entrega } \\
\text { decorrentes da metodologia. }\end{array}$ & \begin{tabular}{|c|} 
Olsson (2007), Houshmand e \\
Jamshidnezhad (2006), Mohammed, \\
Shankar e Banwet (2008), Soon e \\
Udin (2011), Stavrulaki e Davis (2010) \\
e Boyle, Scherrer-Rathje e Stuart (2011) \\
\end{tabular} \\
\hline $\begin{array}{l}\text { 4. Rede de } \\
\text { transportes }\end{array}$ & $\begin{array}{l}\text { Infraestrutura da rede transportes e legislação que possibilite } \\
\text { atender às necessidades decorrentes da metodologia. }\end{array}$ & \begin{tabular}{|} 
Arrto et al. (2008), Sanchez- \\
Rodrigues, Potter e Naim (2010), Wu, \\
Blackhurst e Chidambaram (2006) e \\
Christopher et al. (2011)
\end{tabular} \\
\hline $\begin{array}{l}\text { 5. Cultura } \\
\text { organizacional }\end{array}$ & $\begin{array}{l}\text { Cultura de melhoria contínua, proativa e aberta às } \\
\text { mudanças deve ser desenvolvida na empresa. }\end{array}$ & $\begin{array}{c}\text { Achanga et al. (2006), Bhasin e } \\
\text { Burcher (2006), Jeyaraman e } \\
\text { Teo (2010), Marksberry et al. (2010) e } \\
\text { Yamamoto e Bellgran (2010) }\end{array}$ \\
\hline $\begin{array}{l}\text { 6. Comprometimento } \\
\text { da alta diretoria }\end{array}$ & $\begin{array}{l}\text { Alta diretoria deve fornecer suporte e ser participativa no } \\
\text { processo de implantação da metodologia. }\end{array}$ & $\begin{array}{l}\text { Gattiker e Carter (2010), Young e } \\
\text { Jordan (2008) e Zwikael (2008a, b) }\end{array}$ \\
\hline $\begin{array}{l}\text { 7. Comprometimento } \\
\text { dos colaboradores }\end{array}$ & $\begin{array}{l}\text { Colaboradores devem estar envolvidos e ser participativos } \\
\text { no processo de implantação da metodologia. }\end{array}$ & $\begin{array}{c}\text { Achanga et al. (2006), Anand e } \\
\text { Kodali (2009), Herron e Hicks (2008), } \\
\text { Jeyaraman e Teo (2010), Olivella, } \\
\text { Cuatrecasas e Gavilan (2008), Scherrer- } \\
\text { Rathje, Boyle e Deflorin (2009), } \\
\text { Sim e Rogers (2009) e Worley e } \\
\text { Doolen (2006) }\end{array}$ \\
\hline 8. Liderança & $\begin{array}{l}\text { Comportamento das lideranças deve ser participativo e } \\
\text { consistente com os preceitos da metodologia, fornecendo } \\
\text { uma visão e estratégia adequadas, buscando a integração } \\
\text { de toda a estrutura da empresa na metodologia. }\end{array}$ & $\begin{array}{l}\text { Achanga et al. (2006) e } \\
\text { Emiliani e Stec (2005) }\end{array}$ \\
\hline 9. Treinamento & $\begin{array}{l}\text { Treinamento dos colaboradores deve ser adequado às } \\
\text { necessidades da metodologia e prover ferramentas para sua } \\
\text { implantação. }\end{array}$ & \begin{tabular}{|} 
Achanga et al. (2006), Bhasin e Burcher \\
(2006), Burduk e Chlebus (2006), \\
Jeyaraman e Teo (2010), Lam e Chua \\
(2005), Mathaisel (2005), Olivella, \\
Cuatrecasas e Gavilan (2008) e \\
Sawhney et al. (2010) \\
\end{tabular} \\
\hline 10. Comunicação & $\begin{array}{l}\text { Comunicação entre os diferentes níveis da empresa deve } \\
\text { ser aberta, informando o andamento do projeto, bem } \\
\text { como divulgando as metas e prazos aos envolvidos na } \\
\text { implantação da metodologia. }\end{array}$ & $\begin{array}{c}\text { Aoki (2008), Atkinson, Crawford e } \\
\text { Ward (2006), Jeyaraman e Teo (2010), } \\
\text { Karlsen (2010), Sim e Rogers (2009) e } \\
\text { Worley e Doolen (2006) }\end{array}$ \\
\hline $\begin{array}{l}\text { 11. Configuração do } \\
\text { trabalho }\end{array}$ & $\begin{array}{l}\text { As posições de trabalho devem ser planejadas e } \\
\text { configuradas considerando os preceitos da metodologia. } \\
\text { As atividades e seus tempos devem ser analisados, bem } \\
\text { como as capacidades de máquina devem ser consideradas, } \\
\text { evitando configurar a posição excessivamente lean de } \\
\text { forma a gerar desmotivação nos colaboradores e resistência } \\
\text { em relação à metodologia. }\end{array}$ & $\begin{array}{l}\text { Conti et al. (2006) e Treville e } \\
\text { Antonakis (2006) }\end{array}$ \\
\hline $\begin{array}{l}\text { 12. Autonomia dos } \\
\text { colaboradores }\end{array}$ & $\begin{array}{l}\text { Os colaboradores devem ter autonomia e liberdade para } \\
\text { realizarem mudanças necessárias no processo de produção. }\end{array}$ & $\begin{array}{l}\text { Scherrer-Rathje, Boyle e } \\
\text { Deflorin (2009) }\end{array}$ \\
\hline 13. Visão holística & $\begin{array}{l}\text { A empresa deve ser considerada como um todo durante } \\
\text { o planejamento e execução do projeto de implantação } \\
\text { da metodologia, evitando que os impactos desta sejam } \\
\text { desconsiderados nos diferentes setores. É importante não } \\
\text { se restringir ao setor de manufatura. }\end{array}$ & $\begin{array}{c}\text { Emiliani e Stec (2005), } \\
\text { Mathaisel (2005) e Olsson (2007) }\end{array}$ \\
\hline 14. Gestão do projeto & $\begin{array}{l}\text { Técnicas de gestão de projeto devem ser utilizadas no } \\
\text { projeto de implantação da metodologia. }\end{array}$ & \begin{tabular}{|c|} 
Bhasin e Burcher (2006), Camprieu, \\
Desbiens e Feixue (2007), Howell, \\
Windahl e Seidel (2010), Jeyaraman e \\
Teo (2010), Kutsch (2008), Olivella, \\
Cuatrecasas e Gavilan (2008), Papke- \\
Shields, Beise e Quan (2010), Scherrer- \\
Rathje, Boyle e Deflorin (2009) \\
\end{tabular} \\
\hline
\end{tabular}


Quadro 3. Definições para construção do modelo.

\begin{tabular}{|l|l|}
\hline Problema & Avaliar a probabilidade de sucesso do projeto de implantação da metodologia lean. \\
\hline Cenário de aplicação & $\begin{array}{l}\text { Indústria manufatureira de grande porte (>500 funcionários), em qualquer estágio do } \\
\text { projeto de implantação da metodologia lean. }\end{array}$ \\
\hline Stakeholders & $\begin{array}{l}\text { Engenheiros e gestores envolvidos/responsáveis pelo projeto de implantação da } \\
\text { metodologia lean na empresa. Especialistas em metodologia lean. }\end{array}$ \\
\hline Propriedades & $\begin{array}{l}\text { Considera a sinergia entre os fatores de risco. } \\
\text { Aplicável pela própria empresa sem a necessidade de auxílio externo. } \\
\text { Com base em evidências no processo de autoavaliação da empresa. }\end{array}$ \\
\hline Premissa & $\begin{array}{l}\text { Deficiências em um fator de risco podem ser compensadas pelos demais fatores (elementos } \\
\text { em paralelo). Incapacidade total em um fator de risco causa o insucesso do projeto de } \\
\text { implantação da metodologia lean (subsistemas em série). } \\
\text { Sucesso do projeto corresponde à implantação do sistema lean no prazo previsto, gerando o } \\
\text { benefício esperado de tais sistemas. }\end{array}$ \\
\hline Resultados & $\begin{array}{l}\text { Avaliação da probabilidade de sucesso do projeto de implantação. } \\
\text { Informações que suportem decisões gerenciais visando maximizar a possibilidade de } \\
\text { sucesso do projeto de implantação da metodologia lean. } \\
\text { Identificação dos fatores de risco críticos para priorização de ações gerenciais. }\end{array}$ \\
\hline
\end{tabular}

entre a própria avaliação do fator de risco $i(\mathrm{Si})$ e a compensação que ele poderia prover ao fator $j$ se estivesse em condição excelente $(C i j)$. Esse produto (Si x $C i j$ ) representa a contribuição do respectivo bloco à probabilidade de sucesso da implantação.

A formatação proposta para o modelo atende às condições de contorno do cálculo probabilístico, pois os resultados para a probabilidade de sucesso de cada subsistema e do sistema global permanecem no intervalo esperado para probabilidades.

A autoavaliação da empresa em relação aos fatores de risco foi realizada por formulário estruturado. Este formulário continha a definição dos 14 fatores de risco, um campo para a autoavaliação da empresa em relação aos fatores de risco e outro campo para indicação de evidências que balizassem a avaliação. No campo referente à autoavaliação, a empresa apresentava seu posicionamento em relação aos fatores de risco, atribuindo um valor entre 0 e 1 , sendo 0 , para o caso de a empresa considerar-se totalmente deficiente em relação ao fator de risco, e 1, para o caso de considerar-se plenamente suficiente quanto a esse fator de risco.

A existência de sinergia entre os fatores de risco foi determinada pelo grau de compensação entre fatores de risco. Este foi definido pela mediana das respostas dos cinco especialistas consultados. O modelo resultante foi avaliado e considerado coerente por cinco especialistas na metodologia lean consultados. Os resultados estão apresentados na Tabela 1.

A compensação que o fator $j$ oferece ao fator de risco $i$ é calculada como o produto da multiplicação da própria autoavaliação do fator $j$ pelo grau de compensação que o fator $j$ pode prover ao fator de risco $i$, no caso do fator $j$ estar em condições excelentes. Assim, para que exista compensação, tanto o grau de compensação deve ser diferente de zero (existir sinergia entre $i$ e $j$ ), como a autoavaliação da empresa referente ao fator compensatório deve ser diferente de zero. Logo, a compensação entre fatores de risco dependerá tanto da existência de sinergia entre os fatores de risco, como da situação da empresa relativamente aos fatores de risco, refletindo de forma coerente a situação modelada.

\subsection{Aplicação do modelo e análise dos resultados}

$\mathrm{O}$ estudo foi realizado entre os meses de agosto e novembro de 2011, em três empresas de grande porte localizadas na região sul do Brasil (Quadro 4).

A empresa A está avançada no esforço de implantação da metodologia lean. A unidade avaliada possui diferentes setores com diferentes graus de implantação da metodologia. Ferramentas gerenciais da metodologia, como o relatório A3 e as caminhadas gemba, já são utilizadas. A empresa possui um sistema de gestão de classe mundial, sendo certificada nos padrões da série ISO9000.

As empresas B e C não possuem um plano corporativo de implantação da metodologia lean. As unidades tiveram a iniciativa de implantar preceitos desta metodologia visando melhorarem seus resultados operacionais. Ambas possuem sistemas de gestão de classe mundial, sendo certificadas nos padrões da série ISO9000.

A Tabela 2 apresenta os valores da autoavaliação realizada pelas empresas e o valor corrigido para os fatores de risco devido à sinergia entre fatores, bem como a probabilidade de sucesso do projeto de implantação da metodologia lean calculada.

A Equação 3 exemplifica o cálculo do desempenho compensado para o fator de risco alinhamento estratégico da empresa A, enquanto a Equação 4 demonstra o cálculo para a estimativa da probabilidade de sucesso do projeto de implantação para a empresa A.

Situação compensada do fator de risco alinhamento estratégico: 


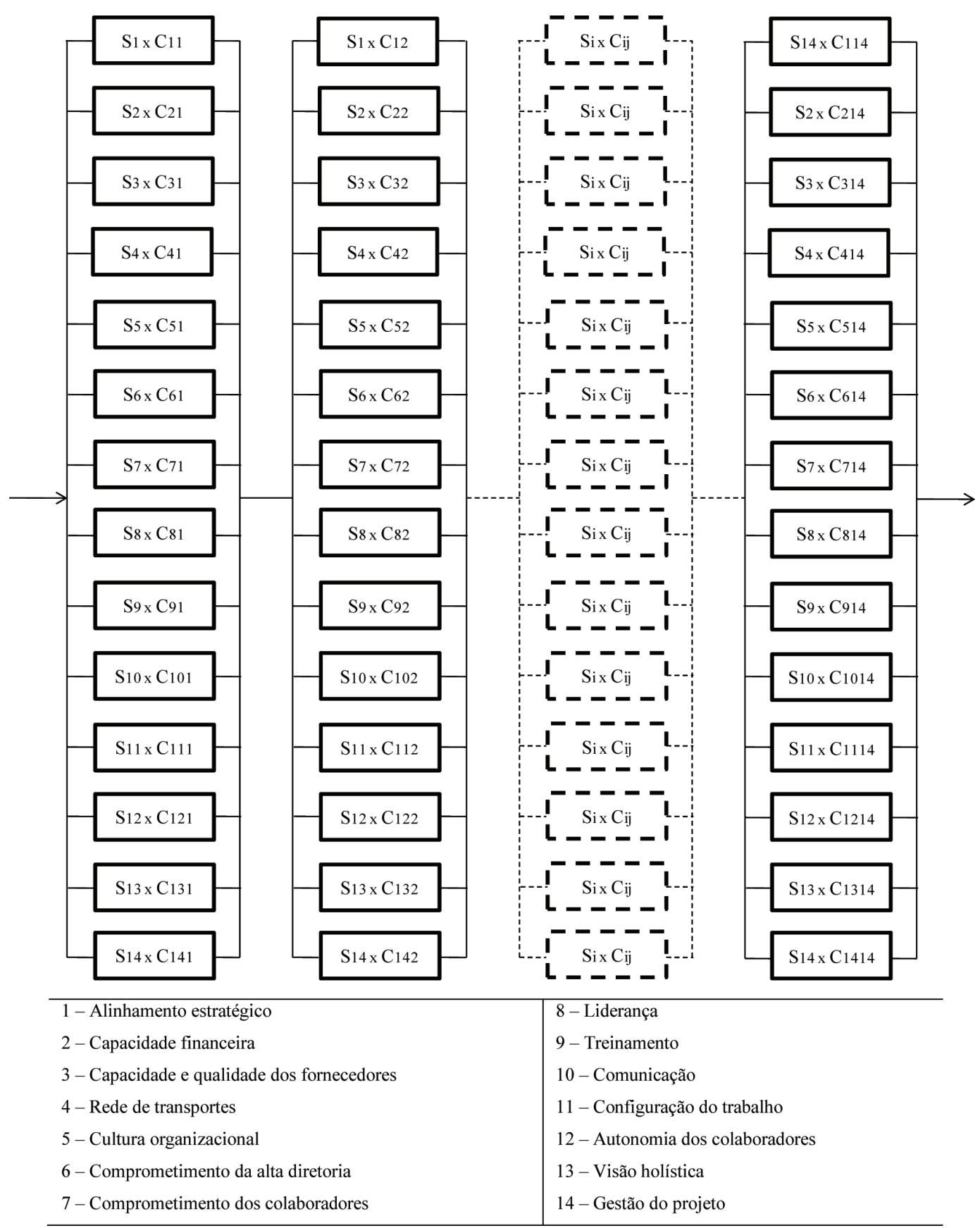

Figura 3. Modelo de sistema série-paralelo proposto.

$$
\text { S1 compensado }=1-\left(\begin{array}{l}
(1-0,60 \times 1) \times(1-0,20 \times 0,30) \times(1-0,20 \times 0) \times \\
(1-1 \times 0) \times(1-0,65 \times 0,60) \times(1-0,65 \times 0,65) \times \\
(1-0,75 \times 0,35) \times(1-0,70 \times 0,40) \times(1-0,85 \times 0,20) \times \\
(1-0,80 \times 0,35) \times(1-0,85 \times 0,05) \times(1-0,80 \times 0) \times \\
(1-0,80 \times 0,35) \times(1-0,95 \times 0,30)
\end{array}\right)=0,979
$$

$\mathrm{PS}_{\mathrm{A}}=0,979 \times 0,882 \times 0,816 \times 1,000 \times 0,994 \times 0,976 \times 0,995 \times 0,984 \times 0,986 \times$

$$
0,986 \times 0,988 \times 0,992 \times 0,978 \times 0,995=0,62
$$


Tabela 1. Grau de compensação entre fatores de risco conforme estabelecido pelos especialistas (valores de $C i j$ ).

\begin{tabular}{|c|c|c|c|c|c|c|c|c|c|c|c|c|c|c|}
\hline & 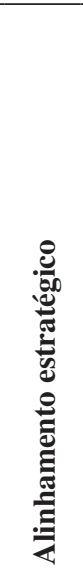 & 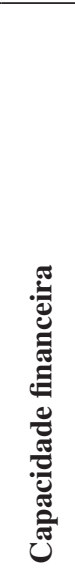 & 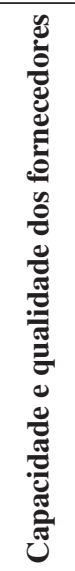 & 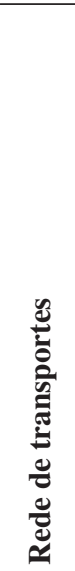 & 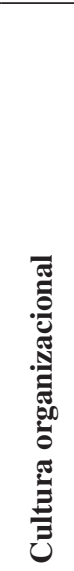 & 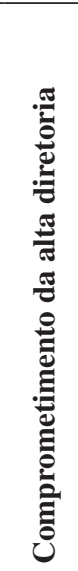 & 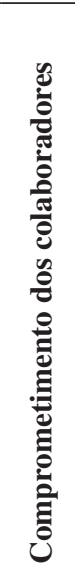 & 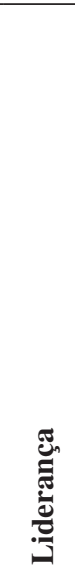 & 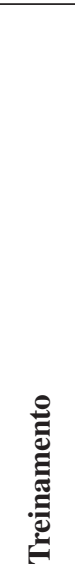 & 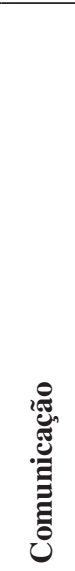 & 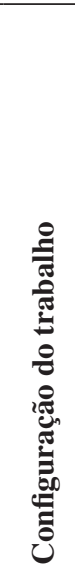 & 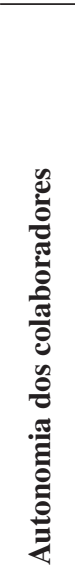 & 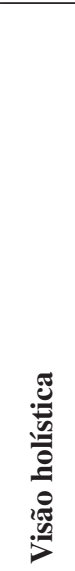 & 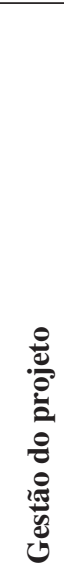 \\
\hline $\begin{array}{l}\text { Alinhamento estratégico } \\
\text { contribui para o(a)... }\end{array}$ & 1 & 0,35 & 0,30 & 0,20 & 0,50 & 0,50 & 0,40 & 0,30 & 0,30 & 0,15 & 0,30 & 0,35 & 0,30 & 0,30 \\
\hline $\begin{array}{l}\text { Capacidade financeira } \\
\text { contribui para o(a)... }\end{array}$ & 0,30 & 1 & 0,30 & 0,20 & 0,30 & 0,40 & 0,25 & 0,30 & 0,30 & 0,20 & 0,30 & 0,15 & 0,10 & 0,30 \\
\hline $\begin{array}{l}\text { Capacidade e qualidade dos } \\
\text { fornecedores contribuem para } \\
\text { o(a)... }\end{array}$ & 0 & 0,40 & 1 & 0,15 & 0,10 & 0 & 0,10 & 0 & 0 & 0 & 0 & 0,05 & 0 & 0,10 \\
\hline $\begin{array}{l}\text { Rede de transportes contribui } \\
\text { para o(a)... }\end{array}$ & 0 & 0,05 & 0,20 & 1 & 0 & 0 & 0 & 0 & 0 & 0 & 0 & 0 & 0 & 0 \\
\hline $\begin{array}{l}\text { Cultura organizacional } \\
\text { contribui para o(a)... }\end{array}$ & 0,60 & 0,15 & 0,20 & 0,10 & 1 & 0,40 & 0,50 & 0,50 & 0,40 & 0,30 & 0,50 & 0,50 & 0,30 & 0,30 \\
\hline $\begin{array}{l}\text { Comprometimento da alta } \\
\text { diretoria contribui para o(a)... }\end{array}$ & 0,65 & 0,35 & 0,20 & 0,10 & 0,60 & 1 & 0,50 & 0,50 & 0,50 & 0,40 & 0,40 & 0,40 & 0,40 & 0,50 \\
\hline $\begin{array}{l}\text { Comprometimento dos } \\
\text { colaboradores contribui para } \\
\text { o(a)... }\end{array}$ & 0,35 & 0,05 & 0,10 & 0.05 & 0,50 & 0,30 & 1 & 0,30 & 0,30 & 0,25 & 0,30 & 0,40 & 0,20 & 0,20 \\
\hline Liderança contribui para o(a)... & 0,40 & 0,05 & 0,10 & 0.05 & 0,65 & 0,35 & 0,50 & 1 & 0,30 & 0,35 & 0,30 & 0,50 & 0,35 & 0,20 \\
\hline Treinamento contribui para o(a)... & 0,20 & 0,25 & 0,15 & 0 & 0,40 & 0,30 & 0,70 & 0,50 & 1 & 0,30 & 0,30 & 0,40 & 0,20 & 0,30 \\
\hline Comunicação contribui para o(a)... & 0,35 & 0,20 & 0,15 & 0,10 & 0,50 & 0,30 & 0,50 & 0,30 & 0,30 & 1 & 0,10 & 0,20 & 0,20 & 0,30 \\
\hline $\begin{array}{l}\text { Configuração do trabalho } \\
\text { contribui para o(a)... }\end{array}$ & 0,05 & 0,20 & 0 & 0 & 0,30 & 0,10 & 0,30 & 0,30 & 0,20 & 0,20 & 1 & 0,30 & 0 & 0,10 \\
\hline $\begin{array}{l}\text { Autonomia dos colaboradores } \\
\text { contribui para o(a)... }\end{array}$ & 0 & 0 & 0 & 0 & 0.30 & 0,15 & 0,30 & 0,15 & 0,10 & 0,10 & 0,10 & 1 & 0 & 0,10 \\
\hline $\begin{array}{l}\text { Visão holística contribui para } \\
\text { o(a)... }\end{array}$ & 0,35 & 0,20 & 0,10 & 0,10 & 0,30 & 0,30 & 0,20 & 0,20 & 0,25 & 0,30 & 0,25 & 0,20 & 1 & 0,30 \\
\hline $\begin{array}{l}\text { Gestão do projeto contribui } \\
\text { para o(a)... }\end{array}$ & 0,30 & 0,30 & 0,20 & 0,10 & 0,30 & 0,30 & 0,20 & 0,20 & 0,15 & 0,50 & 0,35 & 0,35 & 0,50 & 1 \\
\hline
\end{tabular}

Quadro 4. Caracterização das empresas estudadas.

\begin{tabular}{|c|c|c|c|}
\hline Empresa & $\mathbf{A}$ & B & $\mathbf{C}$ \\
\hline Localização & $\begin{array}{c}\text { Região metropolitana de } \\
\text { Porto Alegre / RS }\end{array}$ & $\begin{array}{c}\text { Região metropolitana de } \\
\text { Porto Alegre / RS }\end{array}$ & Norte do Estado de SC \\
\hline Produto & Componentes mecânicos & Componentes eletrônicos & Componentes eletrônicos \\
\hline Origem & $\begin{array}{c}\text { Multinacional com sede na } \\
\text { Alemanha }\end{array}$ & $\begin{array}{l}\text { Multinacional com sede no } \\
\text { Japão }\end{array}$ & $\begin{array}{c}\text { Multinacional com sede no } \\
\text { Brasil }\end{array}$ \\
\hline Tipo de cliente & $\mathrm{B} 2 \mathrm{C}$ & $\mathrm{B} 2 \mathrm{~B}$ & $\mathrm{~B} 2 \mathrm{~B}$ \\
\hline $\begin{array}{l}\text { Principal destino da } \\
\text { produção }\end{array}$ & Mercado externo & Mercado externo & Mercado externo \\
\hline $\mathrm{N}^{\mathrm{o}}$ funcionários unidade & $>1000$ & $>1000$ & $>500$ \\
\hline $\mathrm{N}^{\circ}$ funcionários do grupo & $>16000$ & $>23000$ & $>25000$ \\
\hline
\end{tabular}


Tabela 2. Resultados da avaliação das empresas referentes aos fatores de risco.

\begin{tabular}{|c|c|c|c|c|c|c|}
\hline & \multicolumn{6}{|c|}{ Empresa } \\
\hline & \multicolumn{2}{|c|}{ A } & \multicolumn{2}{|c|}{ B } & \multicolumn{2}{|c|}{$\mathbf{C}$} \\
\hline & $\dot{0}$ & 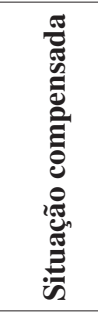 & \multicolumn{2}{|r|}{ 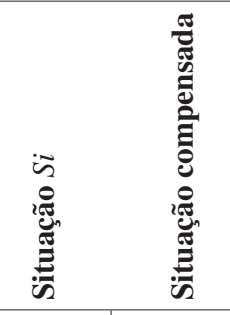 } & \multicolumn{2}{|r|}{ 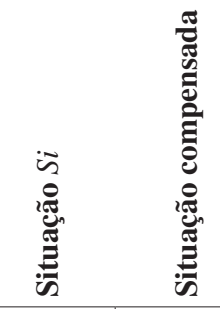 } \\
\hline Alinhamento estratégico & 0,600 & 0,979 & 0,780 & 0,985 & 0,880 & 0,996 \\
\hline Capacidade financeira & 0,200 & 0,882 & 0,750 & 0,958 & 0,450 & 0,933 \\
\hline Capacidade e qualidade dos fornecedores & 0,200 & 0,816 & 0,600 & 0,905 & 0,350 & 0,869 \\
\hline Rede de transportes & 1,000 & 1,000 & 0,600 & 0,819 & 0,650 & 0,845 \\
\hline Cultura organizacional & 0,650 & 0,994 & 0,680 & 0,992 & 0,700 & 0,998 \\
\hline Comprometimento da alta diretoria & 0,650 & 0,976 & 0,730 & 0,978 & 0,900 & 0,995 \\
\hline Comprometimento dos colaboradores & 0,750 & 0,995 & 0,700 & 0,991 & 0,830 & 0,998 \\
\hline Liderança & 0,700 & 0,984 & 0,700 & 0,980 & 0,880 & 0,995 \\
\hline Treinamento & 0,850 & 0,986 & 0,650 & 0,965 & 0,830 & 0,989 \\
\hline Comunicação & 0,800 & 0,986 & 0,550 & 0,949 & 0,800 & 0,987 \\
\hline Configuração do trabalho & 0,850 & 0,988 & 0,600 & 0,964 & 0,850 & 0,991 \\
\hline Autonomia dos colaboradores & 0,800 & 0,992 & 0,650 & 0,981 & 0,830 & 0,995 \\
\hline Visão holística & 0,800 & 0,978 & 0,380 & 0,908 & 0,600 & 0,964 \\
\hline Gestão do projeto & 0,950 & 0,995 & 0,550 & 0,950 & 0,750 & 0,982 \\
\hline Probabilidade de sucesso da implantação lean & \multicolumn{2}{|c|}{0,62} & \multicolumn{2}{|c|}{0,49} & \multicolumn{2}{|c|}{$\mathbf{0 , 6 1}$} \\
\hline
\end{tabular}

Por meio da autoavaliação da empresa A, verificou-se que esta apresentava uma boa situação em relação aos fatores de risco treinamento, comunicação, configuração do trabalho, autonomia dos colaboradores e gestão de projeto, todos avaliados entre 0,8 e 1,0 . Isto ficou evidenciado pela existência de um plano de treinamentos abrangente, o fomento à comunicação dentro da empresa, a análise técnica das posições de trabalho, a utilização da cadeia de ajuda e a utilização de técnicas de gestão de projeto. A empresa mostrou-se deficiente em termos de capacidade financeira e capacidade e qualidade dos fornecedores, avaliados em 0,2. Os valores corrigidos dos fatores de risco, que consideram a compensação provida pelos demais fatores, também indicaram estes como as maiores ameaças ao sucesso do projeto de implantação, resultando em uma probabilidade de sucesso do projeto de implantação de $62 \%$.

O resultado da autoavaliação da empresa B indicou deficiência grande em termos de visão holística $(0,38)$ e moderada em relação à capacidade e qualidade dos fornecedores, rede de transportes, treinamento, comunicação, configuração do trabalho, autonomia dos colaboradores e gestão do projeto. A análise dos valores corrigidos apresenta, como principais fatores de risco, a capacidade e qualidade dos fornecedores, a rede de transportes e a visão holística. A empresa possui um programa de desenvolvimento de fornecedores, mas enfrenta algumas dificuldades com a rede de transporte por utilizar diversas matérias-primas importadas. A probabilidade de sucesso do projeto de implantação calculada ficou abaixo de $50 \%$.

A capacidade financeira, a capacidade e qualidade dos fornecedores, a rede de transportes e a visão holística foram as principais deficiências identificadas pela autoavaliação da empresa C. O exame dos valores corrigidos indica como principais fatores de risco a capacidade e qualidade dos fornecedores, e a rede de transportes, demonstrando as dificuldades enfrentadas pela empresa devido a sua localização e distância dos fornecedores. Resultando em uma probabilidade de sucesso do projeto de implantação de $61 \%$.

A sinergia entre os fatores de risco, indicada pelo valor corrigido no modelo, mostrou um impacto considerável na probabilidade de sucesso do projeto de implantação da metodologia lean. Isto é claramente exemplificado pela relação autoavaliação/situação compensada nos fatores de risco, capacidade financeira e capacidade e qualidade dos fornecedores, encontrada para as empresas A e C (Figura 4).

O modelo também permitiu definir áreas prioritárias de ação, considerando a sinergia entre os fatores. Para a empresa $\mathrm{C}$, a autoavaliação indicou a capacidade financeira como um dos fatores de risco críticos, 


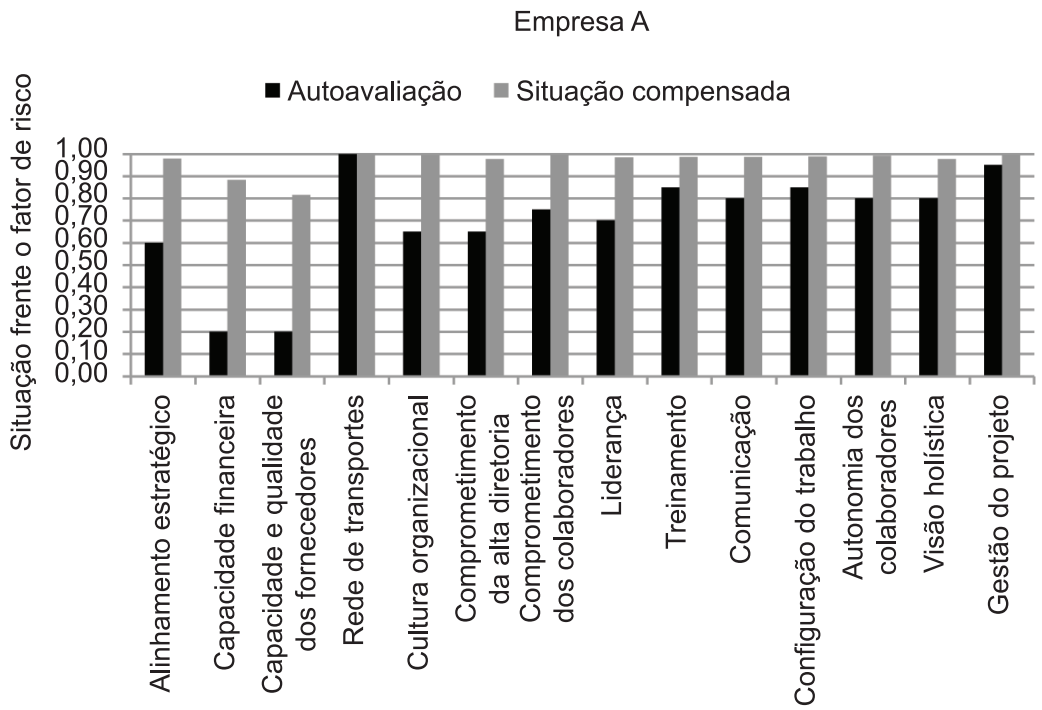

Fator de risco

Empresa C

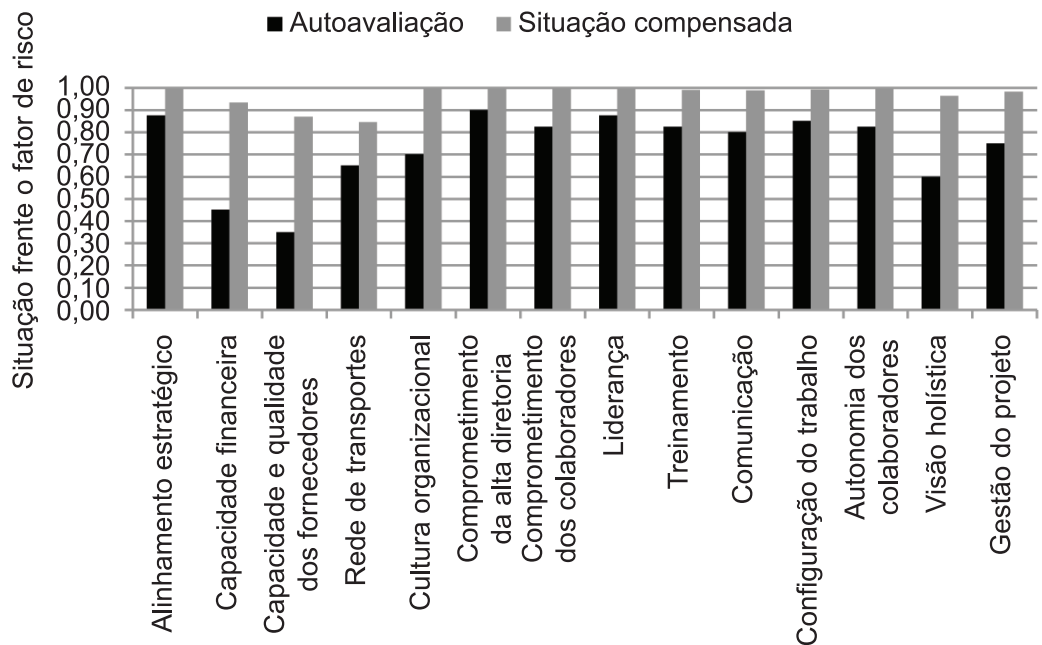

Fator de risco

Figura 4. Situação das empresas A e C referente aos fatores de risco.

porém, analisando a sinergia entre os fatores, outros fatores teriam maior criticidade, como a rede de transportes (ver Figura 4).

O modelo proposto, utilizando fatores de risco configurados em um sistema série-paralelo e conceitos da confiabilidade para cálculo da probabilidade de sucesso do projeto de implantação da metodologia lean, mostrou-se promissor. A primeira impressão das três empresas foi de que a estimativa de probabilidade de sucesso do projeto de implantação da metodologia lean estava baixa. Porém, após discutir os resultados encontrados e as incertezas associadas ao projeto de implantação e aos fatores de risco, considerou-se que os valores eram plausíveis e realistas. As incertezas foram exemplificadas pelo impacto da situação volátil da economia mundial na capacidade financeira das empresas, que afetou diretamente as três empresas por estas atuarem de forma globalizada, exigindo frequente redefinição de projetos e prazos de implantação.

A necessidade de considerar e avaliar a empresa como um todo, bem como a identificação de fatores críticos, considerando a sinergia entre eles, foram destacadas como pontos fortes da metodologia.

\subsection{Avaliação do modelo proposto}

O resultado da aplicação do modelo proposto em projetos de implantação da metodologia lean 
Quadro 5. Comparativo entre modelos de avaliação da implantação da metodologia lean.

\begin{tabular}{|c|c|c|}
\hline Modelo & Considera sinergia entre fatores & $\begin{array}{c}\text { Avalia a probabilidade de sucesso do } \\
\text { projeto de implantação }\end{array}$ \\
\hline Proposto pelos autores & Sim & Sim \\
\hline Bhasin (2011) & $\begin{array}{l}\text { Não, apenas aplica a soma direta de } \\
\text { resultados obtidos em doze categorias. }\end{array}$ & $\begin{array}{l}\text { Não, apenas classifica o resultado final } \\
\text { em um dos sete estágios de implantação } \\
\text { da metodologia lean. }\end{array}$ \\
\hline Goodson (2002) & $\begin{array}{l}\text { Não, apenas aplica a soma direta de } \\
\text { resultados e da quantidade de vezes } \\
\text { respondida sim em onze categorias. }\end{array}$ & $\begin{array}{l}\text { Não, apenas indica o quanto lean está à } \\
\text { empresa. }\end{array}$ \\
\hline Gurumurthy e Kodaly (2009) & $\begin{array}{l}\text { Não, apenas avalia a empresa em } \\
65 \text { elementos avaliados isoladamente. }\end{array}$ & $\begin{array}{l}\text { Não, apenas avalia a situação da empresa } \\
\text { em relação a uma empresa de referência. }\end{array}$ \\
\hline Ray et al. (2006) & $\begin{array}{l}\text { Não, apenas utiliza padrões de } \\
\text { relacionamento entre variáveis } \\
\text { quantificáveis para mensurar uma } \\
\text { variável não diretamente mensurável. }\end{array}$ & $\begin{array}{l}\text { Não, apenas indica o quanto lean está à } \\
\text { empresa. }\end{array}$ \\
\hline Singh, Garg e Sharma (2010) & $\begin{array}{l}\text { Não, apenas aplica em uma função } \\
\text { o resultado da soma da avaliação em } \\
\text { cinco categorias. }\end{array}$ & $\begin{array}{l}\text { Não, apenas indica o quanto lean está a } \\
\text { empresa. }\end{array}$ \\
\hline Soriano-Meier e Forrester (2002) & $\begin{array}{l}\text { Não, apenas aplica a soma direta de } \\
\text { resultados obtidos em onze princípios. }\end{array}$ & $\begin{array}{l}\text { Não, apenas indica o grau de } \\
\text { implantação da metodologia lean. }\end{array}$ \\
\hline Taj (2008) & $\begin{array}{l}\text { Não, apenas aplica a soma direta de } \\
\text { resultados obtidos em nove categorias. }\end{array}$ & $\begin{array}{l}\text { Não, apenas indica a situação atual da } \\
\text { implantação em relação à desejada. }\end{array}$ \\
\hline
\end{tabular}

foi satisfatório. O modelo alcançou o objetivo de indicar de forma quantitativa a probabilidade de sucesso do projeto de implantação da metodologia lean, identificando fatores de risco críticos ao sucesso do projeto, considerando a sinergia entre os fatores de risco. Ele fornece informações que suportam decisões gerenciais para maximizar a possibilidade de sucesso da implantação da metodologia. A lógica de construção e cálculo do modelo permite seu emprego em empresas de portes distintos, bem como diferentes tipos de indústrias. Porém, é preciso fazer a ressalva de que o modelo necessita de um número maior de testes para verificar a aplicabilidade dos graus de sinergia propostos em empresas de portes diferentes.

Ao considerar a sinergia entre fatores e indicar a probabilidade de sucesso do projeto de implantação da metodologia lean, o modelo aborda uma lacuna existente na literatura do tema. O Quadro 5 apresentado a seguir explicita as limitações das abordagens propostas na literatura.

\section{Conclusão}

A gestão de riscos é parte importante de um projeto, provendo os gestores com informações valiosas para a tomada de decisões necessárias ao sucesso do projeto (ABT et al., 2010, AVEN; KRISTENSEN, 2005). Em projetos de implantação da metodologia lean, que apresentam baixa taxa de sucesso (BADURDEEN; WIJEKOON.; MARKSBERRY, 2011; BHASIN; BURCHER, 2006; BOYLE; SCHERRER-RATHJE;
STUART 2011), a identificação dos fatores de risco e gestão ganha relevância.

Este trabalho apresentou um modelo de avaliação dos fatores de risco visando oferecer uma estimativa da probabilidade de sucesso do projeto de implantação da metodologia lean. Baseada em 14 fatores de risco ao sucesso da implantação, identificados na literatura, foi proposta uma estrutura de avaliação baseada nos sistemas série-paralelo. O modelo construído considera a sinergia entre os fatores de risco baseado em indicações fornecidas por especialistas em lean.

A modelagem dos fatores de risco, utilizando a lógica de um sistema série-paralelo, usando preceitos da confiabilidade para a estimativa da probabilidade de sucesso, gerou resultados coerentes. Entre as vantagens desta proposta, ressalta-se o uso de cálculos probabilísticos, que atendem às condições de contorno, de forma que os resultados referentes à probabilidade de sucesso de cada subsistema e do sistema global permanecem no intervalo esperado para probabilidades.

O modelo foi aplicado em três empresas de grande porte localizadas na região sul do Brasil. Os resultados encontrados para a probabilidade de sucesso da implantação do lean nas empresas variaram entre $49 \%$ e $62 \%$ e, conforme a opinião dos profissionais dessas organizações, quantificaram adequadamente as incertezas e riscos presentes nos projetos de implantação avaliados.

Por meio da aplicação do modelo proposto, verificou-se o efeito da sinergia entre fatores de risco e a importância destas. Os estudos de caso demonstraram que os fatores de risco críticos para o 
sucesso do projeto podem diferir daqueles levantados como críticos pelo processo de avaliação direta. Assim, o modelo proposto fornece informações importantes para a tomada de decisões gerenciais mais eficazes. Adicionalmente, o modelo é de fácil operacionalização, tornando viável sua aplicação prática em projetos de implantação da metodologia lean.

Vale observar que os testes do modelo de avaliação foram realizados em três empresas manufatureiras de grande porte, dos setores mecânico e eletrônico. Como sugestões de trabalhos futuros, recomendam-se o uso e o teste do modelo em empresas de porte e indústrias diferentes.

\section{Referências}

ABT, E. et al. Science and Decisions: Advancing Risk Assessment. Risk Analysis, v. 30, n. 7, p. 1028-1036, 2010. PMid:20497395. http://dx.doi. org/10.1111/j.1539-6924.2010.01426.x

ACHANGA, P. et al. Critical Success factors for lean implementation within SMEs. Journal of Manufacturing Technology Management, v. 17, n. 4, p. 460-471, 2006. http://dx.doi.org/10.1108/17410380610662889

ALOINI, D.; DULMIN, R.; MININNO, V. Risk management in ERP project introduction: review of the literature. Information \& Management, v. 44, n. 6, p. 547-567, 2007. http://dx.doi.org/10.1016/j. im.2007.05.004

ANAND, G.; KODALI, R. Selection of lean manufacturing systems using the analytic network process - a case study. Journal of Manufacturing Technology Management, v. 20, n. 2, p. 258-289, 2009. http:// dx.doi.org/10.1108/17410380910929655

AOKI, K. Transferring Japanese kaizen activities to overseas plants in China. International Journal of Operations \& Production Management, v. 28, n. 6, p. 518-539, 2008. http://dx.doi.org/10.1108/01443570810875340

AON. Aon's 2011 Global Risk Management Survey. Aon Corporation, 2011. Disponível em: <http://www. insight.aon.com/?elqPURLPage $=6070>$. Acesso em: 7 maio 2012.

ARENA, M.; ARNABOLDI, M.; AZZONE, G. The organizational dynamics of Enterprise Risk Management. Accounting, Organizations and Society, v. 35, n. 7, p. 659-675, 2010. http://dx.doi.org/10.1016/j. aos.2010.07.003

ARRTO, K. et al. Project strategy: strategy types and their contents in innovation projects. International Journal of Managing Projects in Business, v. 1, n. 1, p. 49-70, 2008. http://dx.doi.org/10.1108/17538370810846414

ATKINSON, R.; CRAWFORD, L.; WARD, S. Fundamental uncertainties in projects and the scope of project management. International Journal of Project Management, v. 24, p. 687-698, 2006. http://dx.doi. org/10.1016/j.ijproman.2006.09.011

AVEN, T.; KRISTENSEN, V. Perspectives on risk: review and discussion of the basis for establishing a unified and holistic approach. Reliability Engineering \&
System Safety, v. 90, n. 1, p. 1-14, 2005. http://dx.doi. org/10.1016/j.ress.2004.10.008

BADURDEEN, F.; WIJEKOON, K.; MARKSBERRY, P. An analytical hierarchy process-based tool to evaluate value systems for lean transformations. Journal of Manufacturing Technology Management, v. 22, n. 1, p. 46-65, 2011. http://dx.doi. org/10.1108/17410381111099806

BHASIN, S. Measuring the Leanness of an organization. International Journal of Lean Six Sigma, v. 2, n. 1, p. 55-74, 2011. http://dx.doi. org/10.1108/20401461111119459

BHASIN, S. BURCHER, P. Lean viewed as a philosophy. Journal of Manufacturing Technology Management, v. 17, n.1, p. 56-72, 2006. http://dx.doi. org/10.1108/17410380610639506

BOYLE, T. A.; SCHERRER-RATHJE, M.; STUART, I. Learning to be lean: the influence of external information sources in lean improvements. Journal of Manufacturing Technology Management, v. 22, n. 5, p. 587-603, 2011. http://dx.doi.org/10.1108/17410381111134455

BURDUK, A.; CHLEBUS, E. Variant simulation in design and risk estimation of manufacturing system. Journal of Manufacturing Technology Management, v. 17, n. 4, p. 448-459, 2006. http:// dx.doi.org/10.1108/17410380610662870

CAMERON, R.; MOLINA-AZORIN, J. F. The acceptance of mixed methods in business and management research. International Journal of Organizational Analysis, v. 19, n. 3, p. 256-271, 2011. http://dx.doi. org/10.1108/19348831111149204

CAMPRIEU, R.; DESBIENS, J.; FEIXUE, Y. 'Cultural' differences in project risk perception: An empirical comparison of China and Canada. Journal of Project Management, v. 25, n. 7, p. 683-693, 2007. http:// dx.doi.org/10.1016/j.ijproman.2007.07.005

CHRISTOPHER, M. et al. Approaches to managing global sourcing risk. Supply Chain Management: An International Journal, v. 16, n. 2, p. 67-81, 2011. http:// dx.doi.org/10.1108/13598541111115338

CONTI, R. et al. The effects of lean production on worker job stress. International Journal of Operations \& Production Management, v. 26, n. 9, p. 1013-1038, 2006. http://dx.doi.org/10.1108/01443570610682616

DELOITTE. Global risk management survey: sixth edition. Risk management in the spotlight. June 2009. Disponível em: <http://www.deloitte.com/assets/ Dcom-Global/Local\%20Assets/Documents/us_fsi_ GlobalRskMgmtSrvy_June09\%281\%29.pdf>. Acesso em: 7 maio 2012.

ELSAYED, E. A. Reliability engineering. Massachusetts: Addison-Wesley, 1996.

EMILIANI, M. L.; STEC, D. J. Leaders lost in transformation. Leadership \& Organization Development Journal, v. 26, n. 5, p. 370-387, 2005. http://dx.doi.org/10.1108/01437730510607862

ERNST \& YOUNG. Recover, adapt, advance. Back to business in an uncertain world. Ernst \& Young Global, 2010. Disponível em: <http://www.ey.com/ Publication/vwLUAssets/Recover-adapt-advance_ back-to-business-in-an-uncertain-world/\$FILE/ 
Recover-adapt-advance_back-to-business-in-anuncertain-world.pdf>. Acessado em: 7 maio 2012.

FOGLIATTO, F. S.; RIBEIRO, J. L. D. Confiabilidade e Manutenção Industrial. São Paulo: Elsevier, 2009. Pmid:18978820.

FINANCIAL TIMES - FT. Global Emerging Risks Survey Steering the Course, Seizing the Opportunity. Financial Times in association with Oliver Wyman, 2010. Disponível em: <http://www.oliverwyman.com/ow/ pdf_files/OW_EN_CR_PUBL_2010_EmergingRisks. pd>. Acesso em: 7 maio 2012.

GATTIKER, T. F.; CARTER, C. R. Understanding project champions' ability to gain intra-organizational commitment for environmental projects. Journal of Operations Management, v. 28, n. 1, p. 72-85, 2010. http://dx.doi.org/10.1016/j.jom.2009.09.001

GODINHO FILHO, M.; FERNANDES, F. C. F. Manufatura Enxuta: uma revisão que classifica e analisa os trabalhos apontando perspectivas de pesquisas futuras. Gestão \& Produção, v. 11, n. 1, p. 1-19, 2004. http://dx.doi. org/10.1590/S0104-530X2004000100002

GOODSON, R. G. Read a plant fast. Harvard Business Review, v. 8, p. 105-113, 2002.

GURUMURTHY, A.; KODALI, R. Application of benchmarking for assessing the lean manufacturing implementation. Benchmarking: An International Journal, v. 16, n. 2, p. 274-308, 2009.

HERRON, C.; HICKS, C. The transfer of selected lean manufacturing techniques from Japanese automotive manufacturing into general manufacturing (UK) through change agents. Robotics and Computer-Integrated Manufacturing, v. 24, n. 4, p. 524-531, 2008. http:// dx.doi.org/10.1016/j.rcim.2007.07.014

HOUSHMAND, M.; JAMSHIDNEZHAD, B. An extended model of design process of lean production systems by means of process variables. Robotics and ComputerIntegrated Manufacturing, v. 22, n.1, p. 1-16, 2006. http://dx.doi.org/10.1016/j.rcim.2005.01.004

HOWELL, D.; WINDAHL, C. M.; SEIDEL, R. H. A. A project contingency framework based on uncertainty and its consequences. International Journal of Project Management, v. 28, n. 3, p. 256-264, 2010. http:// dx.doi.org/10.1016/j.ijproman.2009.06.002

JEYARAMAN, K.; TEO, L. K. A conceptual framework for critical success factors of lean Six Sigma: Implementation on the performance of electronic manufacturing service industry. International Journal of Lean Six Sigma, v. 1, n. 3, p. 191-215, 2010. http://dx.doi. org/10.1108/20401461011075008

JOGULU, U. D.; PANSIRI, J. Mixed methods: a research design for management doctoral dissertations. Management Research Review, v. 34, n. 6, p. 687-701, 2011. http://dx.doi. org/10.1108/01409171111136211

KARLSEN, J. T. Project owner involvement for information and knowledge sharing in uncertainty management. International Journal of Managing Projects in Business, v. 3, n. 4, p. 642-660, 2010. http://dx.doi. org/10.1108/17538371011076091

KRISHNA, H.; SHARMA, R. Estimation of reliability characteristics of general system configuration.
International Journal of Quality \& Reliability Management, v.25, n. 7, p. 772-786, 2008. http:// dx.doi.org/10.1108/02656710810890917

KUTSCH, E. The effect of intervening conditions on the management of project risk. International Journal of Managing Projects in Business, v. 1 , n. 4, p. 602-610, 2008. http://dx.doi. org/10.1108/17538370810906282

LAM, W.; CHUA, A. The mismanagement of knowledge management. Aslib Proceedings, v. 57, n. 5, p. 424-433, 2005. http://dx.doi. org/10.1108/00012530510621879

MALINA, M. A.; NØRREKLIT, H. S.O.; SELTO, F. H. Lessons learned: advantages and disadvantages of mixed method research. Qualitative Research in Accounting \& Management, v. 8, n.1, p. 59-71, 2011. http://dx.doi. org/10.1108/11766091111124702

MARKSBERRY, P. et al. Management directed kaizen: Toyota's Jishuken process for management development. Journal of Manufacturing Technology Management, v. 21, n. 6, p. 670-686, 2010. http:// dx.doi.org/10.1108/17410381011063987

MATHAISEL, D. F. X. A lean architecture for transforming the aerospace maintenance, repair and overhaul (MRO) enterprise. International Journal of Productivity and Performance Management, v. 54, n. 8, p. 623-644, 2005. http://dx.doi.org/10.1108/17410400510627499

McKINSEY. McKinsey Global Survey results: Taking organizational redesign from plan to practice. Dec 2010. Disponível em: <http://www.mckinseyquarterly.com/ Taking_organizational_redesigns_from_plan_to_ practice_McKinsey_Global_Survey_results_2721>. Acesso em: 7 maio 2012.

MOHAMMED, I. R.; SHANKAR, R.; BANWET, D. K Creating flex-lean-agile value chain by outsourcing: An ISM-based interventional roadmap. Business Process Management Journal, v. 14, n. 3, p. 338-389, 2008. http://dx.doi.org/10.1108/14637150810876670

OLIVELLA, J.; CUATRECASAS, L.; GAVILAN, N. Work organisation practices for lean production. Journal of Manufacturing Technology Management, v. 19, n. 7, p. 798-811, 2008. http://dx.doi. org/10.1108/17410380810898750

OLSSON, R. In search of opportunity management: Is the risk management process enough? International Journal of Project Management, v. 25, n. 8, p. 745-752, 2007. http://dx.doi.org/10.1016/j.ijproman.2007.03.005

PAPKE-SHIELDS, K. E.; BEISE, C.; QUAN, J. Do project managers practice what they preach, and does it matter to project success? International Journal of Project Management, v. 28, n. 7, p. 650-662, 2010. http:// dx.doi.org/10.1016/j.ijproman.2009.11.002

QU, S. Q.; DUMAY, J. The qualitative research interview. Qualitative Research in Accounting \& Management, v. 8, n. 3, p. 238-264, 2011. http://dx.doi. org/10.1108/11766091111162070

RAUSAND, M.; HOYLAND, A. System reliability theory: models, statistical methods, and applications. New Jersey: John Wiley \& Sons, 2004. 
RAY, C. D. et al. The lean index: Operational lean metrics for the wood products industry. Wood and Fiber Science, v. 38, n. 2, p. 238-255, 2006.

SANCHEZ-RODRIGUES, V.; POTTER, A.; NAIM, M. Evaluating the causes of uncertainty in logistics operations. International Journal of Logistics Management, v. 21, n. 1, p. 45-64, 2010. http://dx.doi. org/10.1108/09574091011042179

SAURIN, T.; RIBEIRO, J. L. D.; MARODIN, G. A. Identificação de oportunidades de pesquisa a partir de um levantamento da implantação da produção enxuta em empresas do Brasil e do exterior. Gestão \& Produção, v. 17, n. 4, p. 829-841, 2010. http://dx.doi.org/10.1590/ S0104-530X2010000400015

SAWHNEY, R. et al. A modified FMEA approach to enhance reliability of lean systems. International Journal of Quality \& Reliability Management, v. 27, n. 7, p. $832-855,2010$. http://dx.doi. org/10.1108/02656711011062417

SCHERRER-RATHJE, M.; BOYLE, T. A.; DEFLORIN, P. Lean, take two! Reflections from the second attempt at lean implementation. Business Horizons, v. 52, n. 1, p. 79-88, 2009. http://dx.doi.org/10.1016/j. bushor.2008.08.004

SILVA, E. L.; MENEZES, E. M. Metodologia da Pesquisa e Elaboração de Dissertação. Florianópolis: UFSC/ PPGEP/LED, 2001.

SIM, K. L.; ROGERS, J. W. Implementing lean production systems: barriers to change. Management Research News, v. 32, n. 1, p. 37-49, 2009. http://dx.doi. org/10.1108/01409170910922014

SINGH, B.; GARG, S. K.; SHARMA, S. K. Development of index for measuring leanness: study of an Indian auto component industry. Measuring Business Excellence, v. 14, n. 2, p. 46-53, 2010. http://dx.doi. org/10.1108/13683041011047858

SOON, Q. H.; UDIN, Z. M. Supply chain management from the perspective of value chain flexibility: an exploratory study. Journal of Manufacturing Technology Management, v. 22, n. 4, p. 506-526, 2011. http:// dx.doi.org/10.1108/17410381111126427

SORIANO-MEIER, H.; FORRESTER, P. L. A model for evaluating the degree of leanness of manufacturing firms. Integrated Manufacturing
Systems, v. 13, n. 2, p. 104-109, 2002. http://dx.doi. org/10.1108/09576060210415437

STAVRULAKI, E.; DAVIS, M. Aligning products with supply chain processes and strategy. International Journal of Logistics Management, v. 21, n. 1, p. 127-151, 2010. http://dx.doi.org/10.1108/09574091011042214

TAJ, S. Lean manufacturing performance in China: assessment of 65 manufacturing plants. Journal of Manufacturing Technology Management, v. 19, n. 1, p. 217-234, 2008. http://dx.doi. org/10.1108/17410380810847927

TREVILLE, S.; ANTONAKIS, J. Could lean production job design be intrinsically motivating? Contextual, configurational, and levels-of-analysis issues. Journal of Operations Management, v. 24, n. 2, p. 99-123, 2006. http://dx.doi.org/10.1016/j.jom.2005.04.001

WORLEY, J. M.; DOOLEN, T. L. The role of communication and management support in a lean manufacturing implementation. Management Decision, v. 44, n. 2, p. 228-245, 2006. http://dx.doi. org/10.1108/00251740610650210

WU, T.; BLACKHURST, J.; CHIDAMBARAM, V. A model for inbound supply risk analysis. Computers in industry, v. 57, n. 4, p. 350-365, 2006. http://dx.doi. org/10.1016/j.compind.2005.11.001

YAMAMOTO, Y.; BELLGRAN, M. Fundamental mindset that drives improvements towards lean production. Assembly Automation, v. 3, n. 2, p. 124-130, 2010. http://dx.doi.org/10.1108/01445151011029754

YIN, R. K. Case Study Research: Design and Methods. Thousand Oaks: Sage, 2004.

YOUNG, R.; JORDAN, E. Top management support: Mantra or necessity? International Journal of Project Management, v. 26, n. 7, p. 713-725, 2008. http:// dx.doi.org/10.1016/j.ijproman.2008.06.001

ZWIKAEL, O. Top management involvement in project management. Exclusive support practices for different project scenarios. International Journal of Managing Projects in Business, v. 1, n. 3, p. 387-403, 2008a. http://dx.doi.org/10.1108/17538370810883837

ZWIKAEL, O. Top management involvement in project management. A cross country study of the software industry. International Journal of Managing Projects in Business, v. 1, n. 4, p. 498-511, 2008b. http://dx.doi. org/10.1108/17538370810906228 